\title{
The association between high risk of sleep apnea, comorbidities, and risk of COVID-19: a population-based international harmonized study
}

\author{
Frances Chung ${ }^{1,2}\left(\mathbb{D} \cdot\right.$ Rida Waseem $^{1} \cdot$ Chi Pham $^{1,2} \cdot$ Thomas Penzel $^{3} \cdot$ Fang Han $^{4} \cdot$ Bjørn Bjorvatn $^{5,6}$. \\ Charles M. Morin ${ }^{7}$. Brigitte Holzinger ${ }^{8} \cdot$ Colin A. Espie $^{9} \cdot$ Christian Benedict $^{10} \cdot$ Jonathan Cedernaes $^{10,11}$. \\ Tarja Saaresranta ${ }^{12}$. Yun Kwok Wing ${ }^{13}$. Michael R. Nadorff ${ }^{14,15} \cdot$ Yves Dauvilliers ${ }^{16}$ • Luigi De Gennaro $^{17,18}$. \\ Guiseppe Plazzi ${ }^{19,20}$ • Ilona Merikanto ${ }^{21}$. Kentaro Matsui ${ }^{22,23}$. Damien Leger ${ }^{24,25}$. Mariusz Sieminski ${ }^{26}$. \\ Sergio Mota-Rolim ${ }^{27,28}$ • Yuichi Inoue ${ }^{29,30}$ • Markku Partinen ${ }^{31}$ • for the International COVID Sleep Study (ICOSS) group
}

Received: 27 February 2021 / Revised: 31 March 2021 / Accepted: 2 April 2021 / Published online: 28 April 2021

(C) The Author(s), under exclusive licence to Springer Nature Switzerland AG 2021

\begin{abstract}
Purpose Obstructive sleep apnea (OSA) may increase the risk of severe COVID-19; however, the level of potential modulation has not yet been established. The objective of the study was to determine the association between high risk of OSA, comorbidities, and increased risk for COVID-19, hospitalization, and intensive care unit (ICU) treatment.

Methods We conducted a cross-sectional population-based web survey in adults in 14 countries/regions. The survey included sociodemographic variables and comorbidities. Participants were asked questions about COVID-19, hospitalization, and ICU treatment. Standardized questionnaire (STOP questionnaire for high risk of OSA) was included. Multivariable logistic regression was conducted adjusting for various factors.

Results Out of 26,539 respondents, 20,598 (35.4\% male) completed the survey. Mean age and BMI of participants were $41.5 \pm$ 16.0 years and $24.0 \pm 5.0 \mathrm{~kg} / \mathrm{m}^{2}$, respectively. The prevalence of physician-diagnosed OSA was $4.1 \%$ and high risk of OSA was 9.5\%. We found that high risk of OSA (adjusted odds ratio (aOR) 1.72, 95\% confidence interval (CI): 1.20, 2.47) and diabetes (aOR 2.07, 95\% CI: 1.23, 3.48) were associated with reporting of a COVID-19 diagnosis. High risk for OSA (aOR 2.11, 95\% CI: 1.10-4.01), being male (aOR: 2.82, 95\% CI: 1.55-5.12), having diabetes (aOR: 3.93, 95\% CI: 1.70-9.12), and having depression (aOR: 2.33 , 95\% CI: 1.15-4.77) were associated with increased risk of hospitalization or ICU treatment.

Conclusions Participants at high risk of OSA had increased odds of having COVID-19 and were two times more likely to be hospitalized or treated in ICU.
\end{abstract}

Keywords Obstructive sleep apnea $\cdot$ COVID-19 $\cdot$ STOP questionnaire $\cdot$ Diabetes $\cdot$ Depression

\section{Introduction}

Globally, it is estimated that nearly one billion adults have obstructive sleep apnea (OSA), with the highest prevalence in China, followed by the USA, Brazil, and India [1]. OSA is characterized by collapse of the upper airway during sleep, which leads to interruption in breathing, intermittent

Frances Chung

Frances.chung@uhn.ca

Extended author information available on the last page of the article hypoxemia, and frequent arousals. It is estimated that $82 \%$ of men and $93 \%$ of women with moderate to severe sleep apnea are undiagnosed in the general population [2]. A simple screening tool such as the STOP questionnaire (snoring, tiredness, observed apnea, blood pressure) is useful to identify individuals at risk of sleep apnea before laboratory polysomnography or home sleep apnea testing $[3,4]$.

Since January 2020, the coronavirus disease 2019 (COVID-19) pandemic has significantly impacted global health and individual well-being. The severe acute respiratory syndrome coronavirus-2 virus is highly contagious and causes fever, cough, fatigue, respiratory distress, and death. Patients with OSA have a significantly increased risk of severe 
COVID-19, as well as hospitalization and mortality due to COVID-19 [5-13]. OSA has been hypothesized to increase COVID-19 severity and risk of death through proinflammatory pathways $[13,14]$. However, the reported low levels of diagnosed OSA in an obese population with COVID-19 could reflect under-diagnosis of the disorder [15]. Since OSA is an emerging key risk factor for increased severity of COVID-19, screening for OSA may optimize the triage process in COVID-19 patients [5].

Previous studies on the association between diagnosed OSA and COVID-19 have so far examined hospitalized patients in a single country or retrospectively examined electronic medical records of COVID-19-hospitalized patients with OSA [5-13]. To the best of our knowledge, there has been no study on OSA, or at high risk of OSA, and COVID-19 in the general population. Although OSA increases the risk of severe COVID-19, the level of potential modulation has not yet been established. The objective of our study was to determine the associations between high risk of OSA, comorbidities, and increased risk of being afflicted by COVID-19, as well as the risk of hospitalization or intensive care unit (ICU) treatment in a large sample of participants from 14 different countries/regions. We hypothesized that there would be associations between those at high risk of OSA - as well as its comorbidities - with greater risk of being diagnosed with COVID-19 and increased risk of hospitalization or requiring ICU treatment.

\section{Methods}

\section{Global survey during the COVID-19 pandemic}

The research protocol and the final standardized survey questionnaire have been published previously [16]. All countries/ regions obtained ethical approval or exemptions in keeping with national research governance and regulations. The cross-sectional survey data were collected online in each country/region in their native language (translated and then back translated) between May and August 2020. It was administered in 14 countries/regions (Austria, Brazil, Canada, China/Hong Kong, China/Jinlin, Finland, France, Germany, Italy, Japan, Norway, Sweden, UK, and USA).

The International COVID-19 Sleep Study (ICOSS) included sociodemographic variables such as age, gender, marital status, and comorbidities. Participants were asked questions about having been diagnosed with COVID-19, and whether they were hospitalized or treated in the ICU for COVID-19. To investigate sleep problems, standardized and validated questionnaires were included such as Basic Nordic Sleep Questionnaire and STOP questionnaire (snoring, tiredness, observed apnea, pressure) and Patient Health Questionnaire (PHQ)-4 for anxiety and depression $[3,17,18]$. The STOP and PHQ questionnaires have been validated for use in diverse geographical populations $[4,19,20]$.

The survey was administered online by sharing a link on national newspapers, social media sites, and university/ hospital webpages. Participants aged 18 years or older anonymously and voluntarily took part in the self-administered online survey. The most commonly used survey platforms for administration were Redcap and Qualtrics.

\section{High risk of OSA (STOP questionnaire) and comorbidities}

The STOP questionnaire is a screening questionnaire that consists of four yes/no questions on snoring, tiredness, observed apnea, and high blood pressure. Answering yes to at least two of these questions had been shown to be an effective screening tool for high-risk OSA. It has been validated by labpolysomnography [3, 4]. All respondents included in the analysis completed the STOP questionnaire. In the ICOSS survey, instead of answering yes or no, participants provided ratings on 5-point Likert scales for snoring, tiredness, observed apnea (never, less than once per week, 1-2 days per week, 3-5 days per week, and daily or almost daily), and blood pressure (yes/ no) [3]. The questions were as follows: (1) Do you snore loudly (louder than talking or loud enough to be heard through closed doors)? (2) Do you often feel tired, fatigued, or sleepy during daytime? (3) Has anyone observed you stop breathing or choking during your sleep? (4) Do you have or are you being treated for high blood pressure? The first three questions were dichotomized into $0=$ less than three nights per week versus $1=$ three or greater than three nights per week. The highest possible STOP score was four. STOP scores of two or greater were classified as high risk and a score of zero to one as low-risk of OSA [3]. Participants were asked (yes or no questions) whether they suffered from any comorbidities eliciting reports of physician-diagnosed diseases such as sleep apnea, cardiovascular disorder, hypertension, cerebrovascular disorder, diabetes, asthma, chronic obstructive lung diseases (COPD), depression, anxiety, insomnia, other sleep disorder, rheumatic disorder, autoimmune disease, chronic fatigue syndrome, attention deficit hyperactivity disorder, cancer, allergy, and other neurological disorder.

\section{Statistical analysis}

The analyses were performed using STATA/SE 14.2, and participants' characteristics were summarized using mean $( \pm$ standard deviation) scores or percentages (frequency counts). An independent sample $t$-test or chi-square was conducted to investigate potential differences in sociodemographics of participants with high risk of OSA vs low risk of OSA and OSA vs no-OSA. Multivariable logistic regression analyses, with 95\% confidence intervals $(\mathrm{CI})$, were conducted to examine 
the association between high risk of OSA and risk of COVID19, hospitalization, and ICU treatment, adjusting for BMI, age, gender, marital status, education, ethnicity, financial suffering, confinement, and other comorbidities. We chose the variables for models based on clinical importance and their association with the dependent variable in the unadjusted analysis. Some analyses were stratified and weighted by countries. A $P$-value less than 0.05 was considered statistically significant (2-sided).

\section{Results}

A total of 26,539 participants responded to the survey, of whom 20,598 (65\% F) provided complete data on both STOP questionnaire and the presence of comorbidities and were included in the analysis. The sample had a mean age of $41.5 \pm 16.0$ years and a BMI of $24.0 \pm 5.0 \mathrm{~kg} / \mathrm{m}^{2}$. Fifty-five percent were cohabiting/married, and $64 \%$ had bachelors or higher-level education. The most commonly reported comorbidities were hypertension (11\%), cardiovascular diseases (CVD) (4\%), diabetes (4\%), OSA (4\%), depression (8\%), and insomnia (7\%) (Table 1). In total, 9.5\% had a STOP score two or greater and were deemed to be at high risk of OSA. Eight percent of participants reported scores in keeping with high risk of OSA but did not indicate having OSA. There was a significant difference in the sociodemographics in high-risk vs low-risk OSA groups and in OSA vs non-OSA (Table 1). Three percent $(622 / 20,598)$ reported having had COVID-19, of whom $56 \%$ had been confirmed by laboratory testing.

\section{Characteristics and risk factors of participants with COVID-19}

To examine the association between being at high risk of OSA and a reported diagnosis of COVID-19, we adjusted for participants' characteristics and comorbidities. Participants with higher BMI $\left(>35 \mathrm{~kg} / \mathrm{m}^{2}\right)$ (adjusted odds ratio (aOR) 1.91, 95\% CI: 1.08, 3.40), Hispanics ethnicity (aOR 1.55, 95\% CI: 1.05 , 2.30 ), high risk of OSA (aOR 1.72, 95\% CI: 1.20, 2.47), and diabetes (aOR 2.07, 95\% CI: 1.23, 3.48) had higher odds of reporting a COVID-19 diagnosis (Table 2). The unadjusted analyses are shown in eTable 1 .

\section{Risk factors associated with increased hospitalization and ICU treatment}

In total, 622 participants reported having had COVID-19 infection, of whom 536 reported the disease severity level as follows: $42 \%$ reported having mild, $43 \%$ moderate, $12.5 \%$ severe, and $1.9 \%$ life-threatening COVID infection symptoms. Of 104 participants who were hospitalized, $86.5 \%$ were admitted to hospital ward, while $13.5 \%$ were treated in ICU.
Of 431 participants who were not hospitalized, $77.3 \%$ were treated at home, while $22.7 \%$ required no treatment.

To examine if there was an association between high risk of OSA (based on STOP questionnaire) and increased hospitalization for COVID-19, we adjusted for BMI, age, gender, and comorbidities. This analysis was not weighted and stratified due to limited and inconsistent number of responses across countries/regions. High risk of OSA, being male, having diabetes, and having depression were associated with increased hospitalization and ICU treatment related to COVID-19. Participants at high risk of OSA (aOR 2.11, 95\% CI: 1.10 4.01) and having depression (aOR: 2.33, 95\% CI: 1.15-4.77) were at twofold increased odds of hospitalization and ICU treatment for COVID-19 versus low risk of OSA and no depression. Male sex (aOR: 2.82, 95\% CI: 1.55-5.12) and diabetes (aOR: 3.93, 95\% CI: 1.70-9.12) had three times higher odds of being hospitalized and receiving ICU care for COVID-19, compared with female and no diabetes (Table 3). The unadjusted analyses are shown in eTable 2. Figure 1 displays probability values for the significant variables.

\section{Sleep problems and OSA (high risk; reported)}

During the time of confinement of COVID-19 pandemic, we found that the prevalence of self-reported sleep problems such as poor sleep quality, sleep onset, sleep maintenance, early morning awakening problems, nightmares, hypnotic use, fatigue, and excessive sleepiness were significantly increased in participants with risk of OSA (high risk vs low risk) and for OSA vs no-OSA (Fig. 2).

To examine the association between sleep problems during the pandemic and high risk of OSA as well as OSA, we adjusted for gender, age, BMI, marital status, ethnicity, education, presence of sleep problem before COVID-19 pandemic, duration of COVID-19 confinement, financial suffering, comorbidities, and the severity of the COVID-19 epidemic in each country. Analyses were weighted and stratified by countries/regions (eTable 3). There were a significant association between high risk of OSA and all sleep problems. For example, high risk of OSA was most strongly associated with largest increase for excessive sleepiness (aOR 2.42, 95\% CI: 1.90-3.09). Additionally, there was an association between some sleep problems and OSA (eTable 3).

\section{Discussion}

We found that participants with high risk of OSA and diabetes had higher odds of becoming afflicted by COVID- 19 . Additionally, our study showed that participants with the following characteristics - high risk of OSA, being male, having diabetes, and having depression-were two to three times 
Table 1 Sociodemographics characteristics of participants

\begin{tabular}{|c|c|c|c|c|c|}
\hline Variables & $N=20,598^{\mathrm{a}}$ & $\begin{array}{l}\text { STOP <2 } \\
18,645(90.5)\end{array}$ & $\begin{array}{l}\text { STOP } \geq 2 \\
1953(9.5)\end{array}$ & $\begin{array}{l}\text { No-OSA } \\
19,758(95.9)\end{array}$ & $\begin{array}{l}\text { OSA } \\
840(4.1)\end{array}$ \\
\hline Age, years $(n=20,243)$ & $41.5 \pm 16.0$ & $40.9 \pm 16.0$ & $47.1 \pm 15.0^{* *}$ & $41.1 \pm 16.0$ & $51.3 \pm 14.9^{* *}$ \\
\hline Range & $18-98$ & $18-95$ & $18-98$ & $18-98$ & $18-84$ \\
\hline \multicolumn{6}{|l|}{ Gender } \\
\hline Male & $7288(35.4)$ & $6228(33.4)$ & $889(45.5)^{* *}$ & $12,916(65.4)$ & $370(44.1)^{* *}$ \\
\hline Female & $13,286(64.5)$ & $12,397(66.5)$ & $1060(54.3)$ & $6818(34.5)$ & $470(56.0)$ \\
\hline Other & $9(0.1)$ & $8(0.04)$ & $1(0.05)$ & $9(0.05)$ & 0 \\
\hline Missing & $15(0.07)$ & $12(0.06)$ & $3(0.15)$ & $15(0.08)$ & 0 \\
\hline Body mass index, $\mathrm{kg} / \mathrm{m}^{2}(n=19,683)$ & $24.0 \pm 5.0$ & $23.7 \pm 4.7$ & $27.0 \pm 6.4^{* *}$ & $23.9 \pm 4.8$ & $27.7 \pm 6.6^{* *}$ \\
\hline Range & $15-60$ & $15-60$ & $15-60$ & $15-60$ & $16-59$ \\
\hline \multicolumn{6}{|l|}{ Marital status } \\
\hline Single & 7724 (37.5) & $7296(39.1)$ & $428(21.8)^{* *}$ & $7531(38.1)$ & $193(23.0)^{* *}$ \\
\hline Cohabiting & $11,303(54.9)$ & 9997 (53.6) & $1306(66.9)$ & $10,778(54.6)$ & $525(62.5)$ \\
\hline Others & $1518(7.4)$ & $1307(7.0)$ & $211(10.8)$ & $1401(7.1)$ & $117(13.9)$ \\
\hline Missing & $53(0.26)$ & $45(0.24)$ & $8(0.4)$ & $48(0.2)$ & $5(0.6)$ \\
\hline \multicolumn{6}{|l|}{ Education } \\
\hline Less than bachelors & $7104(34.5)$ & $6470(34.7)$ & $634(32.5)^{*}$ & $6808(34.5)$ & $296(35.2)$ \\
\hline Bachelors or higher & $13,210(64.1)$ & $11,914(63.9)$ & $1296(66.4)$ & $12,676(64.1)$ & $534(63.6)$ \\
\hline Missing & $284(1.4)$ & $261(1.4)$ & $3(1.2)$ & $274(1.4)$ & $10(1.2)$ \\
\hline \multicolumn{6}{|l|}{ Ethnicity } \\
\hline Caucasian & $8417(41.0)$ & $7655(41.1)$ & $762(39.0)^{* *}$ & $8133(41.2)$ & $284(33.8) * *$ \\
\hline Asian & $8868(43.1)$ & 8127 (43.6) & $741(37.9)$ & $8490(43.0)$ & $378(45.0)$ \\
\hline Black & $429(2.1)$ & $276(1.5)$ & $153(7.8)$ & $405(2.1)$ & $24(2.9)$ \\
\hline Hispanic & $782(3.8)$ & $680(3.6)$ & $102(5.2)$ & $754(3.8)$ & $28(3.3)$ \\
\hline Other & $1824(9.0)$ & $1662(8.9)$ & $162(8.3)$ & $1708(8.6)$ & $116(13.8)$ \\
\hline Missing & $278(1.4)$ & $245(1.3)$ & $33(1.7)$ & $268(1.4)$ & $10(1.2)$ \\
\hline \multicolumn{6}{|l|}{ COVID-19 } \\
\hline No & $16,165(78.5)$ & $14,667(78.7)$ & $1498(76.7)^{* *}$ & $15,488(78.4)$ & $677(80.6)^{* *}$ \\
\hline Yes & $622(3)$ & $464(2.5)$ & $158(8.1)$ & $582(3.0)$ & $40(4.8)$ \\
\hline Do not know & $3792(18.4)$ & $3496(18.8)$ & $296(15.2)$ & 3669 (18.6) & $123(14.6)$ \\
\hline Missing & $19(0.09)$ & $18(0.10)$ & $1(0.05)$ & $19(0.1)$ & 0 \\
\hline \multicolumn{6}{|l|}{ Confinement } \\
\hline None to 3 weeks & $11,955(58.0)$ & $10,911(58.5$ & $1044(53.5)^{* *}$ & $11,451(58.0)$ & $504(60)$ \\
\hline 4 weeks or less & $2800(13.6)$ & $2461(13.2)$ & $339(17.4)$ & $2676(13.5)$ & $124(14.8)$ \\
\hline More than 4 weeks & $5647(27.4)$ & $5093(27.3)$ & $554(28.4)$ & $5445(27.6)$ & $202(24.0)$ \\
\hline Missing & $196(0.95)$ & $180(1.0)$ & $16(0.8)$ & $186(0.94)$ & $10(1.2)$ \\
\hline \multicolumn{6}{|l|}{ Financial suffering } \\
\hline None to little & $14,799(71.8)$ & $13,577(72.8)$ & $1222(62.6)^{* * *}$ & 14,244 & $555(66.1)^{* *}$ \\
\hline Somewhat & $3155(15.3)$ & 2814(15.1) & $341(17.5)$ & $3023(15.3)$ & $132(132)$ \\
\hline Much to severely & $2616(12.7)$ & $2320(12.4)$ & $386(19.8)$ & 2463 & $153(18.2)$ \\
\hline Missing & $28(0.14)$ & $24(0.13)$ & $4(0.20)$ & $28(0.14)$ & 0 \\
\hline \multicolumn{6}{|l|}{ Comorbidities } \\
\hline $\mathrm{STOP} \geq 2$ & & - & - & $1561(7.9)$ & $392(46.7)^{* *}$ \\
\hline OSA $(n=20,598)$ & $840(4.1)$ & $448(2.4)$ & $392(20.1)^{* *}$ & - & - \\
\hline Insomnia $(n=19,828)$ & $1346(6.8)$ & $1099(6.1)$ & $247(13.1)^{* *}$ & $1,147(6.0)$ & $199(25.1)^{* *}$ \\
\hline Excessive daytime sleepiness $(n=20,577)$ & $3380(16.4)$ & $2700(14.5)$ & $680(34.9)^{* *}$ & $3,157(16.0)$ & $223(26.6)^{* *}$ \\
\hline Hypertension $(n=19,828)$ & $2269(11.4)$ & $1530(8.5)$ & $739(39.2)^{* *}$ & $1939(10.2)$ & $330(41.2)^{* *}$ \\
\hline Cardiovascular disease $(n=20,598)$ & $766(3.7)$ & $575(3.1)$ & $191(9.8)^{* *}$ & $610(3.1)$ & $156(18.6)^{* *}$ \\
\hline Cerebrovascular disease $(n=19,828)$ & $297(1.5)$ & $198(1.1)$ & $99(5.3)^{* *}$ & $213(1.1)$ & $84(10.6) * *$ \\
\hline Diabetes $(n=20,598)$ & $891(4.3)$ & $594(3.2)$ & $297(15.2)^{* *}$ & $706(3.6)$ & $185(22.0)^{* *}$ \\
\hline Autoimmune disease $(n=19,828)$ & $880(4.4)$ & $750(4.2)$ & $130(6.9)^{* *}$ & $757(4.0)$ & $123(15.5)^{* *}$ \\
\hline Neurological disorder $(n=20,598)$ & $589(2.9)$ & $457(2.5)$ & $132(6.8) * *$ & $465(2.4)$ & $124(14.8)^{* *}$ \\
\hline Asthma $(n=6811)^{\mathrm{b}}$ & $587(8.6)$ & $502(7.9)$ & $86(20.1)^{* *}$ & $537(8.3)$ & $50(16.5)^{* *}$ \\
\hline $\operatorname{COPD}(n=19,828)$ & $267(1.4)$ & $185(1.0)$ & $82(4.4)^{* *}$ & $168(0.9)$ & $99(12.5)^{* *}$ \\
\hline Allergy $(n=20,598)$ & $5558(27.0)$ & $5025(27.0)$ & $533(27.3)$ & $5217(26.4)$ & $341(40.6)^{* *}$ \\
\hline Neoplasm/cancer $(n=20,598)$ & $588(2.7)$ & $474(2.5)$ & $84(4.3)^{* *}$ & $474(2.5)$ & $84(4.3)^{* *}$ \\
\hline Anxiety $(n=19,828)$ & $2071(10.4)$ & $1810(10.1)$ & $261(13.8)^{* *}$ & $1871(9.8)$ & $200(25.2)^{* *}$ \\
\hline Depression $(n=19,828)$ & $1682(8.5)$ & $1359(7.6)$ & $323(17.1)^{* *}$ & $1462(7.7)$ & $220(27.7)^{* *}$ \\
\hline Chronic fatigue $(n=19,828)$ & $444(2.2)$ & $328(1.8)$ & $116(6.2)^{* *}$ & $307(1.6)$ & $137(17.3)^{* *}$ \\
\hline
\end{tabular}

Independent sample $t$-test or chi-square test was conducted to test the difference for high risk of OSA vs low-risk of OSA (using STOP questionnaire) and OSA (reported) vs No-OSA. $* * P<0.001, * P<0.05$. OSA obstructive sleep apnea, COPD chronic obstructive pulmonary disease. ${ }^{\text {a }}$ Total number of participants were 20,598 but $n$ varied for some variables. ${ }^{b}$ Due to low number of responses, asthma was not analyzed in the multivariable analysis 
Table 2 Characteristics and risk factors of participants with COVID-19 infection

\begin{tabular}{|c|c|c|c|}
\hline COVID-19 infection & $\begin{array}{l}\text { No COVID } \\
19,957 \\
N(\%)\end{array}$ & $\begin{array}{l}\text { COVID } \\
622 \\
N(\%)\end{array}$ & $\begin{array}{l}\text { Adjusted odds } \\
\text { ratio }[95 \% \mathrm{CI}]\end{array}$ \\
\hline \multicolumn{4}{|l|}{ Age, years } \\
\hline$<26$ & $3614(18.1)$ & $89(14.3)$ & 1 [reference] \\
\hline $26-45$ & $8423(42.2)$ & $339(54.5)$ & $1.41(0.92-2.16)$ \\
\hline $46-65$ & $5616(28.1)$ & $158(25.4)$ & $1.03(0.59-1.81)$ \\
\hline$>65$ & $1958(9.8)$ & $29(4.7)$ & $1.20(0.49-2.94)$ \\
\hline \multicolumn{4}{|l|}{ Gender } \\
\hline Female & 12,897 & $376(60.4)$ & 1 [reference] \\
\hline Male & $7038(35.3)$ & $245(39.3)$ & $1.19(0.88-1.60)$ \\
\hline \multicolumn{4}{|c|}{ Body mass index, $\mathrm{kg} / \mathrm{m}^{2}$} \\
\hline$<25$ & $12,905(64.7)$ & $292(46.9)$ & 1 [reference] \\
\hline $25-35$ & $5570(27.9)$ & $221(35.5)$ & $1.27(0.95-1.70)$ \\
\hline$>35$ & $641(3.2)$ & $38(6.1)$ & $1.91(1.08-3.40)^{*}$ \\
\hline \multicolumn{4}{|l|}{ Ethnicity } \\
\hline Caucasian & $8030(40.2)$ & $373(60)$ & 1 [reference] \\
\hline Asian & $8788(44.0)$ & $80(12.9)$ & $0.52(0.26-1.04)$ \\
\hline Black & $365(1.8)$ & $63(10.1)$ & $1.25(0.78-2.0)$ \\
\hline Hispanic & $719(3.6)$ & $62(10)$ & $1.55(1.05-2.30)^{*}$ \\
\hline Others & $1784(8.9)$ & $38(6.1)$ & $0.31(0.18-0.56)^{*}$ \\
\hline \multicolumn{4}{|l|}{ Risk of OSA } \\
\hline Low & $18,163(91.0)$ & $464(74.6)$ & 1 [reference] \\
\hline High & $1794(9.0)$ & $158(25.4)$ & $1.72(1.20-2.47)^{*}$ \\
\hline \multicolumn{4}{|l|}{ Diabetes } \\
\hline No & $19133(95.8)$ & $556(89.4)$ & 1 [reference] \\
\hline Yes & $824(4.1)$ & $66(10.6)$ & $2.07(1.23-3.48)^{*}$ \\
\hline \multicolumn{4}{|l|}{ Cardiovascular diseases } \\
\hline No & 19,239 (96.4) & $574(92.2)$ & 1 [reference] \\
\hline Yes & $718(3.6)$ & $48(7.7)$ & $1.79(0.99-3.25)$ \\
\hline \multicolumn{4}{|l|}{ Depression } \\
\hline No & 17,613 (88.3) & $515(82.8)$ & 1 [reference] \\
\hline Yes & $1596(8.0)$ & 85 (13.7) & $1.34(0.92-1.95)$ \\
\hline
\end{tabular}

Model was adjusted for body mass index, age, gender, marital status (single, cohabiting, others), ethnicity (Caucasian, Asian, Black, Hispanic, others), education (less than university, university degree), presence of COVID-19, financial suffering (to some extent, somewhat, severely), confinement ( $<2$ weeks, $2-4$ weeks, over 5 weeks), and the severity of the COVID-19 epidemic in each country measured by cumulative number of cases per 100,000 at the median time of the survey in each country. All variables were categorized. Results are weighted and stratified by countries. $C I$ confidence interval, $O S A$ obstructive sleep apnea. $* P<0.05$, $* * P<0.001$ more likely to have been hospitalized or to require ICU treatment due to COVID-19. To the best of our knowledge, our study is the first in the literature focusing on hitherto undiagnosed OSA by using the STOP questionnaire and the risk of COVID-19, whereas previous studies examined COVID-19hospitalized patients with physician-diagnosed OSA [5-13].

The common risk factors for poor outcomes of COVID-19 are older age, hypertension, and diabetes [21, 22], all of which are prevalent or associated with OSA. Clinical recognition of OSA is markedly underdiagnosed worldwide. Previous studies which reported OSA in COVID-19 patients recruited hospitalized patients, usually from one area, with no comparison to participants who had not been afflicted by COVID-19. A few retrospective studies, which examined the association between diagnosed OSA and COVID-19 in electronic medical databases, identified OSA as a risk factor for COVID-19 severity with higher ICU admission and mortality [5-13]. Screening patients for OSA is being recommended to aid in decisions for COVID19 treatment $[5,7]$. Our study is novel as we examined the risk of COVID-19 hospitalization and ICU treatment in individuals with high risk of OSA - using the STOP questionnaire, from a diverse and global general population of over 20,000 individuals. 
Table 3 Risk factors of participants with increased hospitalization and ICU treatment

\begin{tabular}{|c|c|c|c|}
\hline Treatment severity & $\begin{array}{l}\text { No treatment/at home } \\
431 \\
N(\%)\end{array}$ & $\begin{array}{l}\text { Ward/ICU-Hospitalization } \\
104 \\
N(\%)\end{array}$ & $\begin{array}{l}\text { Adjusted odds ratio } \\
{[95 \% \mathrm{CI}]}\end{array}$ \\
\hline \multicolumn{4}{|l|}{ Age, years } \\
\hline$<26$ & $68(15.8)$ & $9(8.7)$ & 1 [reference] \\
\hline $26-45$ & $230(53.4)$ & $67(64.4)$ & $1.63(0.64-4.13)$ \\
\hline$>45$ & $126(29.2)$ & $28(26.9)$ & $0.96(0.33-2.78)$ \\
\hline \multicolumn{4}{|l|}{ Gender } \\
\hline Female & $284(65.9)$ & $39(37.5)$ & 1 [reference] \\
\hline Male & $146(33.9)$ & $65(62.5)$ & $2.82(1.55-5.12)^{* *}$ \\
\hline \multicolumn{4}{|c|}{ Body mass index, $\mathrm{kg} / \mathrm{m}^{2}$} \\
\hline$<25$ & $202(46.9)$ & $46(44.2)$ & 1 [reference] \\
\hline $25-35$ & $164(38.1)$ & $30(28.8)$ & $0.71(0.39-1.29)$ \\
\hline$>35$ & $32(7.4)$ & $1(1.0)$ & $0.15(0.02-1.22)$ \\
\hline \multicolumn{4}{|l|}{ Risk of OSA } \\
\hline Low & $347(80.5)$ & $52(50)$ & 1 [reference] \\
\hline High & $84(19.5)$ & $52(50)$ & $2.11(1.10-4.01)^{*}$ \\
\hline \multicolumn{4}{|l|}{ Diabetes } \\
\hline No & $403(93.5)$ & $79(76.0)$ & 1 [reference] \\
\hline Yes & $28(6.4)$ & $25(24.0)$ & $3.93(1.70-9.12)^{*}$ \\
\hline \multicolumn{4}{|c|}{ Cardiovascular diseases } \\
\hline No & $406(94.2)$ & $88(84.6)$ & 1 [reference] \\
\hline Yes & $25(5.8)$ & $16(15.4)$ & $1.62(0.59-4.45)$ \\
\hline \multicolumn{4}{|l|}{ COPD } \\
\hline No & 407 (94.4) & $87(83.7)$ & 1 [reference] \\
\hline Yes & $11(2.6)$ & $8(7.7)$ & $0.85(0.14-5.29)$ \\
\hline \multicolumn{4}{|l|}{ Depression } \\
\hline No & $370(85.8)$ & $68(65.4)$ & 1 [reference] \\
\hline Yes & $48(11.1)$ & $27(26.0)$ & $2.33(1.15-4.77)^{*}$ \\
\hline
\end{tabular}

Model was adjusted for body mass index, age, gender, and comorbidities. All variables were categorized. ICU intensive care unit, $C I$ confidence interval, $O S A$ obstructive sleep apnea, $C O P D$ chronic obstructive pulmonary disease $* P<0.05, * * P<0.001$
The proinflammatory status of OSA may enhance the typical COVID-19 cytokine storm, thus worsening disease evolution [15]. Interestingly, we observed a significant association between high risk of OSA (STOP score 2 or higher) and increased COVID-19 hospitalization and ICU treatment. In contrast to the literature, we did not observe a significant association between physician-diagnosed OSA and worse outcomes in the general population. Many individuals at high risk of OSA are presumably undiagnosed and have not received treatment, whereas we hypothesized that those who reported physician-diagnosed OSA in our study might have received prehospital and/or in-hospital benefit of treatment such as continuous positive airway pressure (CPAP) possibly accounting for better outcomes. CPAP therapy decreases the underlying proinflammatory conditions which may help manage COVID-19 symptoms by reducing upper airway and systemic oxidative stress $[7,23]$. COVID-19 patients with OSA treated with CPAP prescription appeared to have better outcomes in a study from electronic health records of the New England Health Care System [7].

Among patients with acute respiratory distress syndrome (ARDS) due to COVID-19, undiagnosed SDB was independently associated with ARDS [10]. It is difficult to know the true prevalence of OSA among patients with COVID-19 as diagnostic sleep studies with polysomnography are not feasible at the time of COVID-19 infection. Since our study shows that participants at high risk of OSA are about two times more likely to need hospitalization or ICU care due to COVID-19, therefore, we recommend screening for OSA in order to enhance the COVID-19 triage process. The STOP questionnaire has been validated as an effective tool for OSA screening [3, 4], and its use could aid in predicting COVID-19 severity and the need for more intensive in-hospital treatment.

Consistent with the literature, we found that individuals with diabetes had an increased (three times) odds of being hospitalized for COVID-19. Two meta-analyses found that diabetes was the 

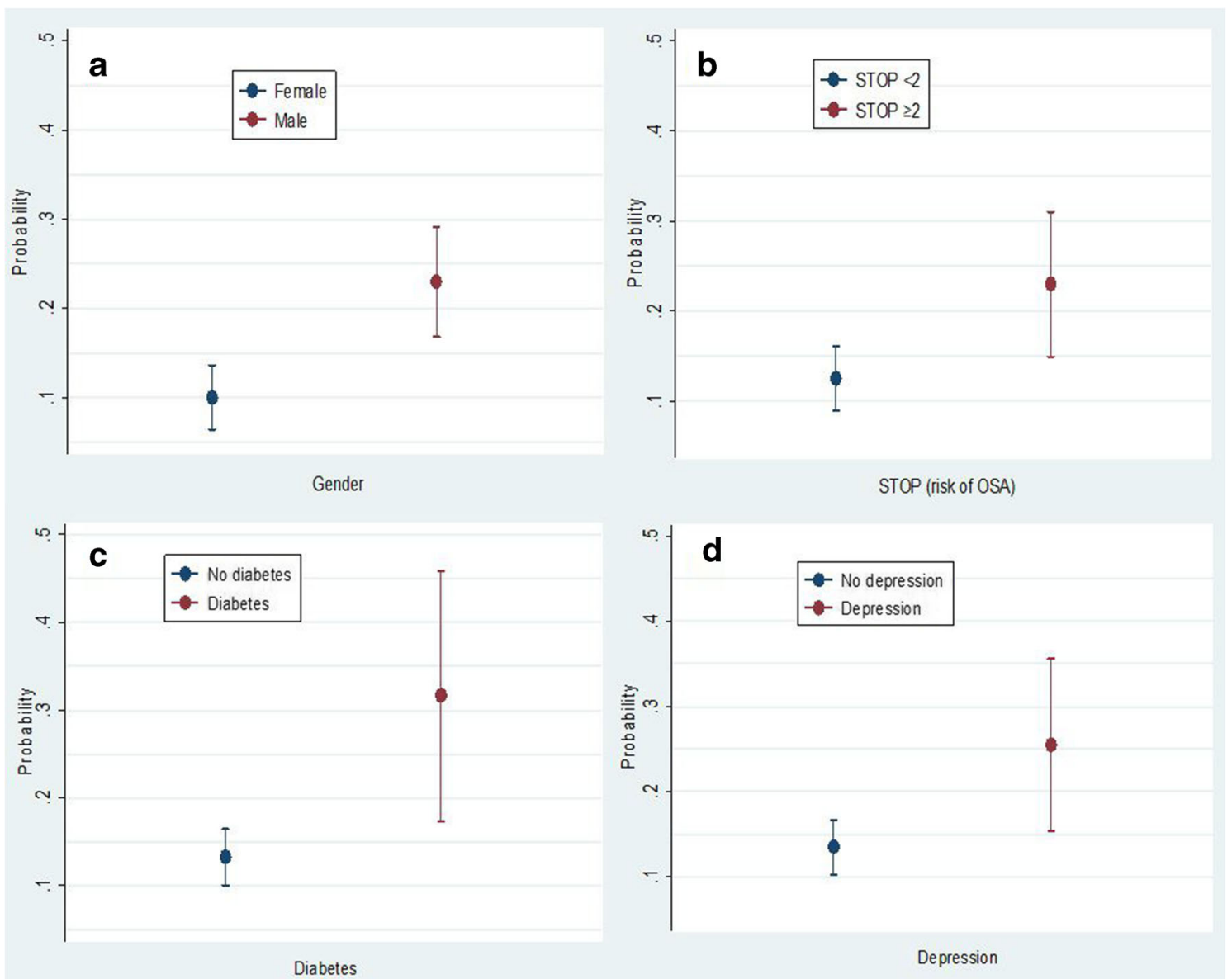

Fig. 1 Predicted probabilities of hospitalization/ICU related to COVID for gender (a), STOP (risk of OSA) (b), diabetes (c), and depression (d). Vertical lines show $95 \%$ confidence interval.

second most prevalent comorbidity in COVID-19 patients [24, 25]. Patients with diabetes are often treated with angiotensin converting enzyme (ACE) inhibitors, which result in upregulation of the protein ACE2 [26]. The SARS-CoV-2 virus uses the enzyme as its main receptor to gain entry into the host cells [27]. Individuals with high risk of diabetes are thus potentially more likely to experience COVID-19 severe symptoms due to the increased expression of ACE2.

We showed that males were at three-fold increased odds of being hospitalized for COVID infection. Our findings are consistent with the previous studies which showed an increased risk of hospitalization and mortality in males compared to females [21, 22, 28, 29].

There are high rates of depression in individuals with OSA in both community and clinical populations [30]. Up to 20\% of those presenting with a diagnosed depressive syndrome may have OSA, and vice versa [31]. In our survey, we asked participants whether they have a physician-diagnosed depression. Importantly, we found that participants who reported depression had almost two-fold increased odds of hospitalization due to COVID-19. Our findings are supported by two recent studies. Wang et al. analyzed a US-wide database of electronic health records of 61 million patients. Patients with depression had over 7-folds increased risk for COVID-19 with a higher rate of death and hospitalization [32]. Also, Atkins et al. reported that in 269,070 older adults, a pre-existing diagnosis of depression emerged as an independent risk factor for COVID-19 hospitalization [21]. However, it is plausible that depression may be a consequence of COVID-19 as a result of having been ill or critically ill for a substantial period. Further research is needed to validate if COVID-19 hospitalization is due to pre-existing depression itself or secondary to other conditions.

Previous studies found age, hypertension, and COPD to be risk factors for mortality and hospitalization in COVID-19hospitalized patients [21, 22, 28, 33], but we did not find an association for these variables. However, our study involved general population using an online platform. The participants in our study were younger, with fewer comorbidities, such as hypertension and COPD, than previous studies on COVID19-hospitalized patients [5-13].

We found that all types of sleep problems such as poor sleep quality, sleep onset and maintenance problem, daytime fatigue, and sleepiness were associated with high risk vs low 

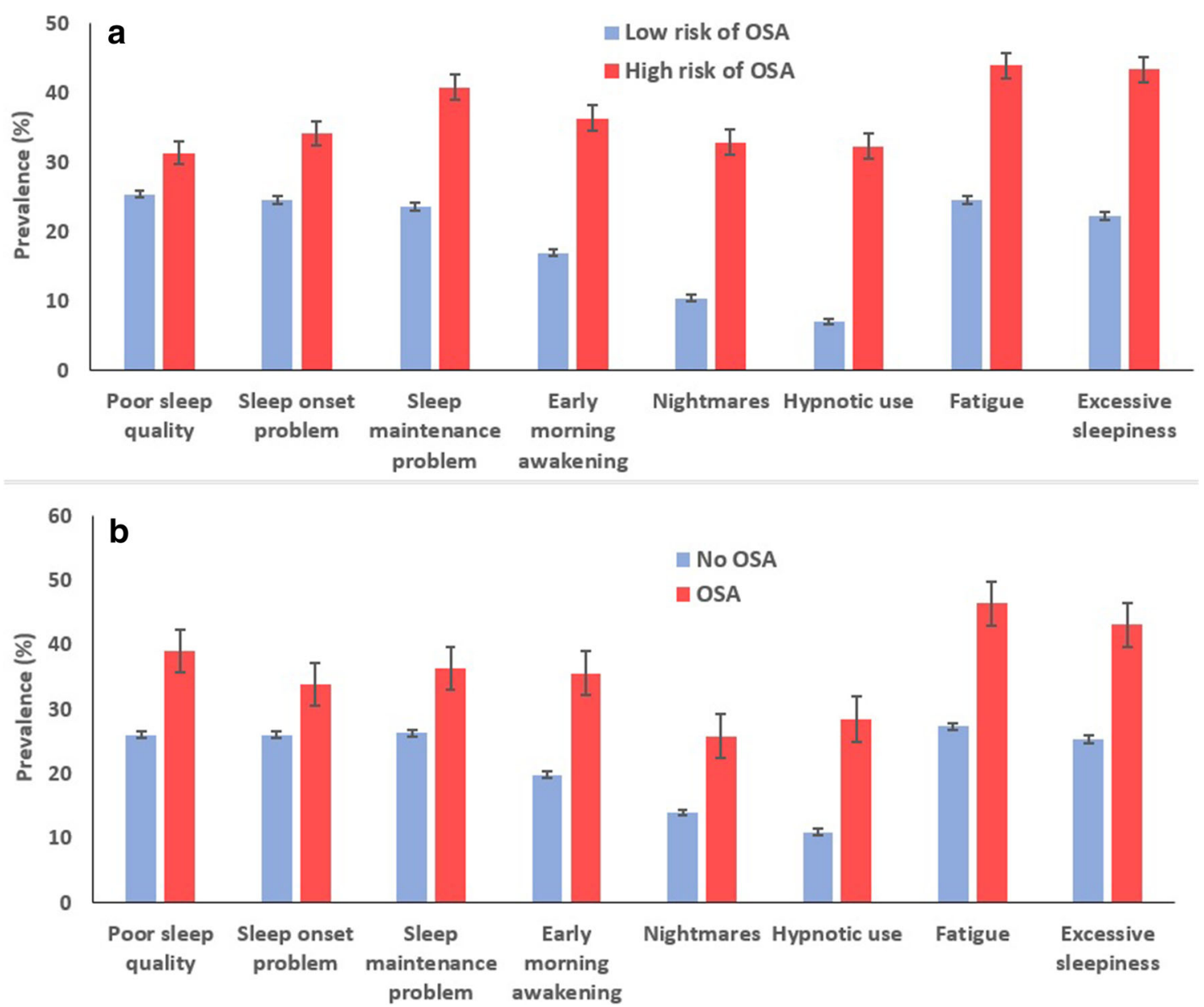

Fig. 2 Prevalence of sleep problems during COVID-19 pandemic for risk of OSA (a) and OSA (b). Vertical lines show standard error. High risk of OSA: STOP score 2 or greater. Low risk of OSA: STOP score less than 2. Chi-square analyses showed that there was a significant difference in the

risk of OSA. OSA is characterized by intermittent complete and partial airway collapse, which results in sleep problems including frequent arousals, disruptive snoring, breathing pauses, and co-occurrence of insomnia [34]. More sleep problems were recorded in participants who were at high risk of OSA based on the STOP questionnaire, compared with those with OSA, which further implies that patients with OSA might have received treatment that was beneficial to their symptoms.

\section{Limitations}

There are several methodological limitations due to the nature of survey-based data collection. Potential inaccuracy from reported data means that we cannot be certain all participants answered each survey question to the best of their ability or knowledge. We conducted the survey using web applications, which only allowed individuals with access to the internet to participate, thus potentially limiting the generalizability of our results. Variations in sample sizes and frame of sampling posed another prevalence of risk of OSA (high vs low) and OSA (yes vs no) for all sleep problems during pandemic $(P<0.001)$. OSA, obstructive sleep apnea; ICU, intensive care unit

limitation and were relative to each different country. These variations were addressed using weighting in some analyses.

Another major limitation is that we used the STOP questionnaire to screen participants for high risk of OSA. Although the STOP questionnaire is a validated screening tool in the population with pulmonary diseases $[35,36]$, it has not been validated to use in patients with COVID-19. It is possible that an inflammatory state such as COVID-19 may produce enough upper airway inflammation to provoke snoring. Dyspnea associated with bilateral COVID-19 pneumonia could be misinterpreted as choking during sleep. These may affect the reliability of the STOP questionnaire in this setting. Hence, our results should be interpreted with caution. Nevertheless, our findings are important as we demonstrated the association between those at high risk of OSA and COVID-19 in the general public in a large dataset. Our results epitomize a large and diverse global population representing different ethnicities and a broad age range. 


\section{Conclusion}

In summary, participants at high risk of OSA had higher odds of reporting having been diagnosed with COVID-19. Furthermore, participants at high risk of OSA were two times more likely to have been treated in a hospital or ICU. Being male, having diabetes, and having depression were also associated with increased risk of hospitalization and ICU treatment. Our study used the STOP questionnaire as a screening tool in the general population to identify individuals with a high risk of OSA. Identifying those at high risk of OSA by screening may enhance the COVID-19 triage process to optimize treatment.

Abbreviations OSA, Obstructive sleep apnea; COVID-19, Coronavirus disease 2019 (caused by severe acute respiratory syndrome coronavirus2); ICU, Intensive care unit; BMI, Body mass index; ACE, Angiotensin converting enzyme

Supplementary Information The online version contains supplementary material available at https://doi.org/10.1007/s11325-021-02373-5.

Acknowledgements We like to acknowledge ICOSS group collaborators:

(1) Ngan Yin Chan, PhD, Li Chiu Kong Family Sleep Assessment Unit, Departments of Psychiatry, Faculty of Medicine, The Chinese University of Hong Kong, Shatin, Hong Kong SAR, China; (2) Courtney J. Bolstad, M.Sc, Department of Psychology, Mississippi State University, Mississippi State, MS, USA; (3) Jules Schneider, $\mathrm{PhD}$, Sleep and Circadian Neuroscience Institute, Nuffield Department of Clinical Neurosciences, University of Oxford, Oxford, UK; (4) Ying Huang, MD, Sleep Medicine Center, Charite Universitätsmedizin Berlin, Berlin, Germany; and (5) Ana Fernandes, BSc, Brain Institute, Federal University of Rio Grande do Norte, Brazil.

Author contribution Chung and Partinen had full access to all of the data in the study and take responsibility for the integrity of the data and the accuracy of the data analysis.

Concept and design: Chung, Penzel, Han, Bjorvatn, Morin, Holzinger, Espie, and Partinen.

Drafting of the manuscript: Chung, Waseem, and Pham.

Statistical analysis: Chung and Waseem.

Acquisition of data: All authors.

Critical revision of the manuscript for important intellectual content: All authors.

Administrative, technical, or material support: Chung, Thomas, Han, Bjorvatn, Morin, Holzinger, Espie, Benedict, Cedernaes, Wing, Nadorff, Dauvilliers, De Gennaro, Plazzi, Matsui, Leger, Sieminski, Mota-Rolim Inoue, and Partinen.

Supervision: Chung, Penzel, Han, Bjorvatn, Morin, Holzinger, Espie, Benedict, Cedernaes, Wing, Nadorff, Dauvilliers, De Gennaro, Plazzi, Matsui, Leger, Sieminski, Mota-Rolim, Inoue, and Partinen.

\section{Declarations}

Ethics approval All procedures performed in studies involving human participants were in accordance with the ethical standards of the institutional and/or national research committee and with the 1964 Helsinki declaration and its later amendments or comparable ethical standards.
Informed consent Informed consent was obtained from all individual participants included in the study.

Competing interests Dr. Chung reports grants from Ontario Ministry of Health Innovation Grant, grants from University Health Network Foundation, and personal fees from Masimo Inc. and Takeda Pharma, outside the submitted work. University Health Network has a patent STOP-Bang questionnaire pending. Dr. Espie reports grants from the Wellcome Trust and NIHR (HTA) and is a co-founder and a shareholder in Big Health, outside of the submitted work. Dr. Inoue reports personal fees and other from Astellas Pharma, personal fees from Eisai, other from Idorsia Pharmaceuticals Japan, grants from Koike Medical, personal fees from Otsuka Pharmaceutical, and grants from Philips Japan, outside the submitted work. Dr. Leger reports grants from Philips (Netherlands), grants from Vanda (USA), grants from Sanofi, grants from VitalAire International, grants from Merck, and grants from Janssen, Jazz, and TYTHM outside the submitted work. Dr. Matsui reports personal fees from Eisai, personal fees from Meiji Seika Pharma, personal fees from Mochida, personal fees from MSD, personal fees from Otsuka Pharmaceutical, and personal fees from Yoshitomi Pharmaceutical, outside the submitted work. Dr. Partinen reports personal fees and other from Bioprojet, other from Jazz Pharmaceuticals, personal fees from UCBPharma, personal fees from GSK, personal fees from Takeda, personal fees and other from MSD, personal fees from Orion, and personal fees and other from Umecrine, outside the submitted work. Dr. Penzel reports personal fees from Jazz Pharmaceuticals, personal fees from Bayer Healthcare, personal fees from Neuwirth, and personal fees from Löwenstein Medical, outside the submitted work, and shareholder of The Siestagroup GmbH, Advanced Sleep Research GmbH, Nukute. Dr. Plazzi reports personal fees from UCB pharma, personal fees from Jazz pharmaceuticals, personal fees from Bioprojet, personal fees from Idorsia, and personal fees from Takeda, outside the submitted work. Dr. Wing reports grants from Research Grant Council General Research Fund, grants from Health and Medical Research Fund, personal fees from Eisai Inc., personal fees from Eisai Co., Ltd., and other from Lundbeck HK Limited, outside the submitted work. Dr. Benedict reports that he served as a paid member of a scientific advisory board for Repha GmBH, Langenhagen, Germany. Dr. Bjorvatn, Mr. Bolstad, Dr. Cedernaes, Dr. Chan, Dr. Dauvilliers, Ms. Fernandes, Dr. De Gennaro, Dr. Han, Dr. Huang, Dr. Holzinger, Dr. Morin, Dr. Mota-Rolim, Dr. Nadorff, Mr. Schneider, Dr. Sieminski, Dr. Saaresranta, Dr. Merikanto, Ms. Waseem, and Ms. Pham have nothing to disclose.

\section{References}

1. Benjafield AV, Ayas NT, Eastwood PR, Heinzer R, Ip MSM, Morrell MJ, Nunez CM, Patel SR, Penzel T, Pepin JL, Peppard PE, Sinha S, Tufik S, Valentine K, Malhotra A (2019) Estimation of the global prevalence and burden of obstructive sleep apnoea: a literature-based analysis. Lancet Respir Med 7(8):687-698. https:// doi.org/10.1016/S2213-2600(19)30198-5

2. Young T, Evans L, Finn L, Palta M (1997) Estimation of the clinically diagnosed proportion of sleep apnea syndrome in middleaged men and women. Sleep 20(9):705-706. https://doi.org/10. 1093/sleep/20.9.705

3. Chung F, Yegneswaran B, Liao P, Chung SA, Vairavanathan S, Islam S, Khajehdehi A, Shapiro CM (2008) STOP questionnaire: a tool to screen patients for obstructive sleep apnea. Anesthesiology 108(5):812-821. https://doi.org/10.1097/ALN.0b013e31816d83e4

4. Chiu HY, Chen PY, Chuang LP, Chen NH, Tu YK, Hsieh YJ, Wang YC, Guilleminault C (2017) Diagnostic accuracy of the Berlin questionnaire, STOP-BANG, STOP, and Epworth sleepiness scale in detecting obstructive sleep apnea: a bivariate meta- 
analysis. Sleep Med Rev 36:57-70. https://doi.org/10.1016/j.smrv. 2016.10.004

5. Maas MB, Kim M, Malkani RG, Abbott SM, Zee PC (2020) Obstructive sleep apnea and risk of COVID-19 infection, hospitalization and respiratory failure. Sleep Breath. https://doi.org/10. 1007/s11325-020-02203-0

6. Miller MA, Cappuccio FP (2021) A systematic review of COVID19 and obstructive sleep apnoea. Sleep Med Rev 55:101382. https://doi.org/10.1016/j.smrv.2020.101382

7. Cade BE, Dashti HS, Hassan SM, Redline S, Karlson EW (2020) Sleep apnea and COVID-19 mortality and hospitalization. Am J Respir Crit Care Med 202(10):1462-1464. https://doi.org/10. 1164/rccm.202006-2252LE

8. Peker Y, Celik Y, Arbatli S, Isik SR, Balcan B, Karatas F, Uzel FI, Tabak L, Cetin B, Baygul A, Ozturk AB, Altug E, Iliaz S, Atasoy C, Kapmaz M, Yazici D, Bayram H, Durmaz Cetin B, Caglayan B, Collaborators O-S (2021) Effect of high-risk obstructive sleep apnea on clinical outcomes in adults with coronavirus disease 2019: a multicenter, prospective, observational cohort study. Ann Am Thorac Soc. https://doi.org/10.1513/AnnalsATS.202011-1409OC

9. Oh TK, Song IA (2021) Impact of coronavirus disease-2019 on chronic respiratory disease in South Korea: an NHIS COVID-19 database cohort study. BMC Pulm Med 21(1):12. https://doi.org/ 10.1186/s12890-020-01387-1

10. Labarca G, Henriquez-Beltran M, Llerena F, Erices G, Lastra J, Enos D, Castillo D, Fraga M, Lamperti L, Ormazabal V, Riffo B, Rubilar D, Sanhueza R, Vasquez J, Villanueva C, Horta G, Sanhueza F, Melo P, Dreyse J, Jorquera J, Fernandez-Bussy S, Gonzalez J, Barbe F, Nova-Lamperti E, Consortium C (2021) Undiagnosed sleep disorder breathing as a risk factor for critical COVID-19 and pulmonary consequences at the midterm followup. Sleep Med. https://doi.org/10.1016/j.sleep.2021.02.029

11. Strausz S, Kiiskinen T, Broberg M, Ruotsalainen S, Koskela J, Bachour A, FinnGen PA, Palotie T, Ripatti S, Ollila HM (2021) Sleep apnoea is a risk factor for severe COVID-19. BMJ Open Respir Res 8(1):e000845. https://doi.org/10.1136/bmjresp-2020000845

12. Lohia P, Sreeram K, Nguyen P, Choudhary A, Khicher S, Yarandi H, Kapur S, Badr MS (2021) Preexisting respiratory diseases and clinical outcomes in COVID-19: a multihospital cohort study on predominantly African American population. Respir Res 22(1):37. https://doi.org/10.1186/s12931-021-01647-6

13. Cariou B, Hadjadj S, Wargny M, Pichelin M, Al-Salameh A, Allix I, Amadou C, Arnault G, Baudoux F, Bauduceau B, Borot S, Bourgeon-Ghittori M, Bourron O, Boutoille D, Cazenave-Roblot F, Chaumeil C, Cosson E, Coudol S, Darmon P, Disse E, DucetBoiffard A, Gaborit B, Joubert M, Kerlan V, Laviolle B, Marchand L, Meyer L, Potier L, Prevost G, Riveline JP, Robert R, Saulnier PJ, Sultan A, Thebaut JF, Thivolet C, Tramunt B, Vatier C, Roussel R, Gautier JF, Gourdy P, investigators C (2020) Phenotypic characteristics and prognosis of inpatients with COVID-19 and diabetes: the CORONADO study. Diabetologia 63(8):1500-1515. https://doi. org/10.1007/s00125-020-05180-x

14. Suen CM, Hui DSC, Memtsoudis SG, Chung F (2020) Obstructive sleep apnea, obesity, and noninvasive ventilation: considerations during the COVID-19 pandemic. Anesth Analg 131(2):318-322. https://doi.org/10.1213/ANE.0000000000004928

15. Perger E, Soranna D, Pengo M, Meriggi P, Lombardi C, Parati G (2021) Sleep-disordered breathing among hospitalized patients with COVID-19. Am J Respir Crit Care Med 203(2):239-241. https:// doi.org/10.1164/rccm.202010-3886LE

16. Partinen M, Bjorvatn B, Holzinger B, Chung F, Penzel T, Espie CA, Morin CM, group IC-c (2021) Sleep and circadian problems during the coronavirus disease 2019 (COVID-19) pandemic: the International COVID-19 Sleep Study (ICOSS). J Sleep Res 30(1): e13206. https://doi.org/10.1111/jsr.13206
17. Partinen M, Gislason T (1995) Basic Nordic Sleep Questionnaire (BNSQ): a quantitated measure of subjective sleep complaints. J Sleep Res 4(S1):150-155. https://doi.org/10.1111/j.1365-2869. 1995.tb00205.x

18. Kroenke K, Spitzer RL, Williams JB, Lowe B (2009) An ultra-brief screening scale for anxiety and depression: the PHQ-4. Psychosomatics 50(6):613-621. https://doi.org/10.1176/appi.psy. 50.6.613

19. Pivetta B, Chen L, Nagappa M, Saripella A, Waseem R, Englesakis M, Chung F (2021) Use and performance of the STOP-Bang questionnaire for obstructive sleep apnea screening across geographic regions: a systematic review and meta-analysis. JAMA Netw Open 4(3):e211009. https://doi.org/10.1001/jamanetworkopen.2021. 1009

20. Carroll HA, Hook K, Perez OFR, Denckla C, Vince CC, Ghebrehiwet S, Ando K, Touma M, Borba CPC, Fricchione GL, Henderson DC (2020) Establishing reliability and validity for mental health screening instruments in resource-constrained settings: systematic review of the PHQ-9 and key recommendations. Psychiatry Res 291:113236. https://doi.org/10.1016/j.psychres. 2020.113236

21. Atkins JL, Masoli JAH, Delgado J, Pilling LC, Kuo CL, Kuchel GA, Melzer D (2020) Preexisting comorbidities predicting COVID-19 and mortality in the UK Biobank community cohort. J Gerontol A Biol Sci Med Sci 75(11):2224-2230. https://doi.org/10. 1093/gerona/glaa183

22. Williamson EJ, Walker AJ, Bhaskaran K, Bacon S, Bates C, Morton CE, Curtis HJ, Mehrkar A, Evans D, Inglesby P, Cockburn J, McDonald HI, MacKenna B, Tomlinson L, Douglas IJ, Rentsch CT, Mathur R, Wong AYS, Grieve R, Harrison D, Forbes H, Schultze A, Croker R, Parry J, Hester F, Harper S, Perera R, Evans SJW, Smeeth L, Goldacre B (2020) Factors associated with COVID-19-related death using OpenSAFELY. Nature 584(7821):430-436. https://doi.org/10.1038/s41586-020-2521-4

23. Karamanli H, Ozol D, Ugur KS, Yildirim Z, Armutcu F, Bozkurt B, Yigitoglu R (2014) Influence of CPAP treatment on airway and systemic inflammation in OSAS patients. Sleep Breath 18(2): 251-256. https://doi.org/10.1007/s11325-012-0761-8

24. Roncon L, Zuin M, Rigatelli G, Zuliani G (2020) Diabetic patients with COVID-19 infection are at higher risk of ICU admission and poor short-term outcome. J Clin Virol 127:104354. https://doi.org/ 10.1016/j.jcv.2020.104354

25. Yang J, Zheng Y, Gou X, Pu K, Chen Z, Guo Q, Ji R, Wang H, Wang Y, Zhou Y (2020) Prevalence of comorbidities and its effects in patients infected with SARS-CoV-2: a systematic review and meta-analysis. Int J Infect Dis 94:91-95. https://doi.org/10.1016/j. ijid.2020.03.017

26. Fang L, Karakiulakis G, Roth M (2020) Are patients with hypertension and diabetes mellitus at increased risk for COVID-19 infection? Lancet Respir Med 8(4):e21. https://doi.org/10.1016/S22132600(20)30116-8

27. Wan Y, Shang J, Graham R, Baric RS, Li F (2020) Receptor recognition by the novel coronavirus from Wuhan: an analysis based on decade-long structural studies of SARS coronavirus. J Virol 94(7). https://doi.org/10.1128/JVI.00127-20

28. Richardson S, Hirsch JS, Narasimhan M, Crawford JM, McGinn T, Davidson KW, the Northwell C-RC, Barnaby DP, Becker LB, Chelico JD, Cohen SL, Cookingham J, Coppa K, Diefenbach MA, Dominello AJ, Duer-Hefele J, Falzon L, Gitlin J, Hajizadeh N, Harvin TG, Hirschwerk DA, Kim EJ, Kozel ZM, Marrast LM, Mogavero JN, Osorio GA, Qiu M, Zanos TP (2020) Presenting characteristics, comorbidities, and outcomes among 5700 patients hospitalized with COVID-19 in the New York City area. JAMA 323(20):2052-2059. https://doi.org/10.1001/jama.2020.6775

29. Scully EP, Haverfield J, Ursin RL, Tannenbaum C, Klein SL (2020) Considering how biological sex impacts immune responses 
and COVID-19 outcomes. Nat Rev Immunol 20(7):442-447. https://doi.org/10.1038/s41577-020-0348-8

30. Harris M, Glozier N, Ratnavadivel R, Grunstein RR (2009) Obstructive sleep apnea and depression. Sleep Med Rev 13(6): 437-444. https://doi.org/10.1016/j.smrv.2009.04.001

31. Schroder CM, O'Hara R (2005) Depression and obstructive sleep apnea (OSA). Ann Gen Psychiatry 4:13. https://doi.org/10.1186/ 1744-859X-4-13

32. Wang Q, Xu R, Volkow ND (2021) Increased risk of COVID-19 infection and mortality in people with mental disorders: analysis from electronic health records in the United States. World Psychiatry 20(1):124-130. https://doi.org/10.1002/wps.20806

33. Bonanad C, Garcia-Blas S, Tarazona-Santabalbina F, Sanchis J, Bertomeu-Gonzalez V, Facila L, Ariza A, Nunez J, Cordero A (2020) The effect of age on mortality in patients with COVID-19: a meta-analysis with 611,583 subjects. J Am Med Dir Assoc 21(7): 915-918. https://doi.org/10.1016/j.jamda.2020.05.045
34. Zhang Y, Ren R, Lei F, Zhou J, Zhang J, Wing YK, Sanford LD, Tang X (2019) Worldwide and regional prevalence rates of cooccurrence of insomnia and insomnia symptoms with obstructive sleep apnea: a systematic review and meta-analysis. Sleep Med Rev 45:1-17. https://doi.org/10.1016/j.smrv.2019.01.004

35. Silva GE, Vana KD, Goodwin JL, Sherrill DL, Quan SF (2011) Identification of patients with sleep disordered breathing: comparing the four-variable screening tool, STOP, STOP-Bang, and Epworth Sleepiness Scales. J Clin Sleep Med 7(5):467-472. https://doi.org/10.5664/JCSM.1308

36. Naranjo M, Willes L, Prillaman BA, Quan SF, Sharma S (2020) Undiagnosed OSA may significantly affect outcomes in adults admitted for COPD in an inner-city hospital. Chest 158(3):11981207. https://doi.org/10.1016/j.chest.2020.03.036

Publisher's note Springer Nature remains neutral with regard to jurisdictional claims in published maps and institutional affiliations.

\section{Affiliations}

\section{Frances Chung ${ }^{1,2}$ (D) $\cdot$ Rida Waseem $^{1} \cdot$ Chi Pham $^{1,2} \cdot$ Thomas Penzel $^{3} \cdot$ Fang Han $^{4} \cdot$ Bjørn Bjorvatn ${ }^{5,6}$.}

Charles M. Morin ${ }^{7} \cdot$ Brigitte Holzinger $^{8} \cdot$ Colin A. Espie $^{9} \cdot$ Christian Benedict $^{10} \cdot$ Jonathan Cedernaes $^{10,11}$. Tarja Saaresranta ${ }^{12}$. Yun Kwok Wing ${ }^{13}$. Michael R. Nadorff ${ }^{14,15} \cdot$ Yves Dauvilliers $^{16} \cdot$ Luigi De Gennaro $^{17,18}$. Guiseppe Plazzi ${ }^{19,20}$ • Ilona Merikanto ${ }^{21}$ • Kentaro Matsui ${ }^{22,23}$ • Damien Leger ${ }^{24,25}$ • Mariusz Sieminski ${ }^{26}$. Sergio Mota-Rolim ${ }^{27,28}$ • Yuichi Inoue ${ }^{29,30}$ • Markku Partinen ${ }^{31}$ • for the International COVID Sleep Study (ICOSS) group

1 Department of Anesthesia and Pain Medicine, Toronto Western Hospital, University Health Network, University of Toronto, Toronto, ON M5T2S8, Canada

2 Institute of Medical Science, Temerty Faculty of Medicine, University of Toronto, Ontario, Canada

3 Sleep Medicine Center, Charite Universitätsmedizin Berlin, Berlin, Germany

4 Department of Respiratory Medicine, Peking University People's Hospital, Beijing, China

5 Department of Global Public Health and Primary Care, University of Bergen, Bergen, Norway

6 Norwegian Competence Center for Sleep Disorders, Haukeland University Hospital, Bergen, Norway

7 École de Psychologie, Centre d'étude des troubles du sommeil, Centre de recherche CERVO/Brain Research Center, Université Laval, Québec, Canada

8 Institute for Dream and Consciousness Research, Medical University of Vienna, Vienna, Austria

9 Sleep and Circadian Neuroscience Institute, Nuffield Department of Clinical Neurosciences, University of Oxford, Oxford, UK

10 Department of Neuroscience, Sleep Science (BMC), Uppsala University, Uppsala, Sweden

11 Division of Endocrinology, Metabolism, and Molecular Medicine, Department of Medicine, Northwestern University, Chicago, IL, USA
12 Division of Medicine, Department of Pulmonary Diseases, Turku University Hospital, Turku, Finland

13 Li Chiu Kong Family Sleep Assessment Unit, Departments of Psychiatry, Faculty of Medicine, The Chinese University of Hong Kong, Shatin, Hong Kong, SAR, China

14 Department of Psychology, Mississippi State University, Starkville, USA

15 Department of Psychiatry and Behavioral Sciences, Baylor College of Medicine, Houston, USA

16 Sleep-Wake Disorders Center, Department of Neurology, Gui-deChauliac Hospital, Institute for Neurosciences of Montpellier INM, INSERM, University of Montpellier, Montpellier, France

17 Department of Psychology, Sapienza University of Rome, Rome, Italy

18 IRCCS Fondazione Santa Lucia, Rome, Italy

19 IRCCS, Istituto delle Scienze Neurologiche di Bologna, Bologna, Italy

20 Department of Biomedical, Metabolic and Neural Sciences, University of Modena and Reggio Emilia, Modena, Italy

21 Department of Psychology and Logopedics and SleepWell Research Program, Faculty of Medicine, University of Helsinki, Helsinki, Finland

22 Department of Clinical Laboratory and Department of Sleep-Wake Disorders, National Center of Neurology and Psychiatry National Institute of Mental Health, Kodaira, Japan 
23 Department of Psychiatry, Tokyo Women's Medical University, Tokyo, Japan

24 Sleep and Vigilance Center, Hopital Hotel-Dieu de Paris, Paris, France

25 Universite de Paris, VIFASOM (EA 7331 Vigilance Fatigue Sommeil et Santé Publique), Paris, France

26 Department of Emergency Medicine, Medical University of Gdansk, Gdansk, Poland

27 Brain Institute, Onofre Lopes University Hospital, Natal, Brazil
28

Physiology and Behavior Department, Federal University of Rio Grande do Norte, Natal, Brazil

29 Department of Somnology, Tokyo Medical University, Tokyo, Japan

30 Japan Somnology Center, Neuropsychiatric Research Institute, Tokyo, Japan

31 Helsinki Sleep Clinic, Vitalmed Research Center, and Department of Neurosciences, Clinicum, University of Helsinki,

Helsinki, Finland 